\title{
DETERMINATION OF CAFFEINE CONTENT IN DIFFERENT BRANDS OF PURE COFFEE, INSTANT COFFEE AND TEA AVAILABLE IN THE NAYPYITAW MARKET
}

\author{
Wai Linn Aung \\ Department of Pharmacology \\ DSMRC, Naypyitaw, Myanmar \\ Thein Min Hlaing \\ Department of Pharmacology \\ DSMRC, Naypyitaw, Myanmar
}

\author{
Moe Kyaw \\ Department of Pharmacology \\ DSMRC, Naypyitaw, Myanmar \\ Thein Zaw \\ Department of Pharmacology \\ DSMRC, Naypyitaw, Myanmar
}

\author{
Kyee Myint \\ Department of Pharmacology \\ DSMRC, Naypyitaw, Myanmar
}

\begin{abstract}
Caffeine is a naturally found in leaves, seeds or fruits of over 63 plants species worldwide and most common sources are coffee, cocoa beans, cola nuts and tea leaves. Caffeine is a pharmacologically active substance and depending on dose, can be mild CNS stimulant, improve cardiac performance, increase heartbeat rate, and increase brain circulation. An excessive intake of caffeine in some persons appears to augment sensitivity of heart to emotional, increase the incidence of extra systoles and other arrhythmias. For healthy adults, USFDA has cited $400 \mathrm{mg} / \mathrm{day}$ - as an amount not generally associated with negative health effects. The objective of this study was to determine caffeine content in different brands of pure coffee, instant coffee and tea available in Naypyitaw market. Pure coffee, instant coffee and tea samples of fourteen different brands collected from retail shops in Naypyitaw were coded into C1-C14. HPLC condition for caffeine was achieved on VP-ODS (C18) column with mobile phase consisting of methanol: water $(50: 50 \% \mathrm{v} / \mathrm{v})$ at a flow rate of $1 \mathrm{~mL} / \mathrm{min}$ and $\mathrm{UV}$ detection at $254 \mathrm{~nm}$. Linearity of method was check from $6.25-100 \mathrm{ppm}$ and correlation coefficient was 0.9999 . The caffeine contents in pure coffee samples were $2.74 \pm 0.111 \mathrm{mg} / \mathrm{g}(\mathrm{C1}), 0.87 \pm 0.003$ $\mathrm{mg} / \mathrm{g}(\mathrm{C} 2), 3.64 \pm 1.39 \mathrm{mg} / \mathrm{g}(\mathrm{C} 3), 5.26 \pm 0.07 \mathrm{mg} / \mathrm{g}(\mathrm{C} 4)$ and $3.03 \pm 0.004 \mathrm{mg} / \mathrm{g}(\mathrm{C} 5)$. The caffeine contents in instant coffee samples were $0.28 \pm 0.003 \mathrm{mg} / \mathrm{g}(\mathrm{C} 6), 0.24 \pm 0.002 \mathrm{mg} / \mathrm{g}$ (C7), 0.4 $\pm 0.009 \mathrm{mg} / \mathrm{g}$ (C8) and $0.31 \pm 0.008 \mathrm{mg} / \mathrm{g}$ (C9). The caffeine contents in tea samples were $0.93 \pm 0.014 \mathrm{mg} / \mathrm{g}$ (C10), 0.92 $\pm 0.002 \mathrm{mg} / \mathrm{g}$ (C11), 0.29 $\pm 0.001 \mathrm{mg} / \mathrm{g}$ (C12), $0.79 \pm 0.004 \mathrm{mg} / \mathrm{g}(\mathrm{C13})$ and $0.63 \pm 0.002 \mathrm{mg} / \mathrm{g}(\mathrm{C14})$. The findings showed pure coffee has highest caffeine content
\end{abstract}

followed by tea and instant coffee. The consumer should drink not more than USFDA recommended caffeine level $(400 \mathrm{mg} /$ day) especially in pure coffee drinker.

Keywords-HPLC, USFDA, Caffeine, CNS, VP-ODS

\section{INTRODUCTION}

Caffeine, an alkaloid of the methylxanthine family is a naturally occurring substance found in the leaves, seeds or fruits of over 63 plants species worldwide. The most commonly known sources of caffeine are coffee, cocoa beans, cola nuts and tea leaves. In its pure state, it is an intensely bitter white powder. Its chemical formula is $\mathrm{C}_{8} \mathrm{H}_{10} \mathrm{~N}_{4} \mathrm{O}_{2}$, its systematic name is 1, 3, 5-trimethylxanthine ${ }^{1}$. Caffeine is a pharmacologically active substance and depending on the dose, can be a mild central nervous system (CNS) stimulant. Caffeine does not accumulate in the body over the course of time and is normally excreted within several hours of consumption $^{2}$

Tea is another common source of caffeine. Although tea contains more caffeine than coffee, a typical serving contains much less, as tea is normally brewed much weaker. Besides strength of the brew, growing conditions, processing techniques and other variables also affect caffeine content. Preparation and many other factors have a significant impact on tea and color is a very poor indicator of caffeine content ${ }^{3}$. Caffeine which is found in tea and coffee imparts bitterness and also acts as a flavor constituent. It is a mild nervous stimulant towards drowsiness and fatigue ${ }^{4}$. 


\section{International Journal of Engineering Applied Sciences and Technology, 2020 Vol. 5, Issue 4, ISSN No. 2455-2143, Pages 500-504 \\ Published Online August 2020 in IJEAST (http://www.ijeast.com)}

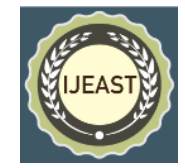

About $200 \mathrm{mg}$ of caffeine contains pharmacological effect. At this level, it stimulates the central nervous system, decreases fatigue leading to clearer flow of thoughts, sustained intellectual effort and a more perfect association of ideas with a better appreciation of sensory stimuli in $\operatorname{man}^{5}$. At this level, it has a diuretic effect on the kidney hence affect fluid balance in the body. It also increase heartbeat rate, dilate blood vessels and elevate levels of free fatty acids and glucose in the plasma $^{6}$. $1 \mathrm{~g}$ of caffeine leads to insomnia, nervousness, nausea, ear ringing, flashing of light delirium and tremulousness ${ }^{7}$.

Caffeine also stimulates the stomach to pour out large amounts of acid. This in turn leads to burning in the pits of the stomach and aggravates peptic ulcers of the stomach and duodenum. It also reduces blood flow to the brain by causing the brains blood vessels to constrict. It also may induce benign (non-cancerous) breast diseases and may worsen pre-menstrual symptoms in women who overuse it ${ }^{8}$. Caffeine crosses the placenta and enters the fetal circulation and its use at a pharmacological level has been associated with low birth weight. Excessive consumption during lactation may cause irritability and wakefulness in a breast- fed baby ${ }^{4}$. Caffeine has a mild analeptic (respiratory stimulating activity) effect. Other action includes cardiac stimulation which may produce tachycardia, dilation of coronary and peripheral blood vessels, constriction of blood vessels and skeletal muscles. It increases the risk of spontaneous abortion in women ${ }^{4}$.

For healthy adults, the USFDA has cited 400 milligrams a day - that's about four or five cups of coffee - as an amount not generally associated with dangerous, negative effects ${ }^{9}$. However, there is wide variation in both how sensitive people are to the effects of caffeine and how fast they metabolize it (break it down $)^{10}$. The USFDA has not set a level for children, but the American Academy of Pediatrics discourages the consumption of caffeine and other stimulants by children and adolescents. The threshold of caffeine toxicity appears to be around $400 \mathrm{mg} /$ day in healthy adults (19 years or older), $100 \mathrm{mg} /$ day in healthy adolescents (12-18 years old), and $2.5 \mathrm{mg} / \mathrm{kg} /$ day in healthy children (less than 12 years old) ${ }^{11}$.

An excessive intake of caffeine in some persons appears to augment the sensitivity of the heart to emotional and other factors and so increase the incidence of extra systoles and other arrhythmias. Since caffeine affect the central nervous system conversely, omission of a habitual morning dosage often results in nervousness, irritability, drowsiness, poor work performance and headache, curable only by taking more caffeine $^{11}$.

As stated earlier, intake of large quantities of caffeine may cause a number of health problems. It is suspected that due to the high frequency of intake, the amount of caffeine consequently taken by people may be significantly high as to cause the health problems mentioned. Coffee and tea are the most popular drinks in Myanmar too.

Therefore, the objective of this study was to determine the level of caffeine in different brands of pure coffee, instant coffee and tea available in the Naypyitaw market in order to establish whether the amount of caffeine in the beverages is so much as to cause adverse health problems. In this study, high performance liquid chromatography (HPLC) method was employed since it is simple and reliable technique.

\section{OBJECTIVES}

General objective

To determine caffeine content in different brands of pure coffee, instant coffee and tea available in the Naypyitaw market.

Specific objectives

1. To determine caffeine content in different brands of pure coffee, instant coffee and tea by High Performance Liquid Chromatography (HPLC) method.

2. To evaluate caffeine content in different brands of pure coffee, instant coffee and tea by accepted daily intake that defined by USFDA.

\section{RESEARCH METHODOLOGY}

Study design

The study was used laboratory based descriptive study.

Study population

Pure coffee, instant coffee and tea samples available in the Naypyitaw Market was used in this study.

Study site

This study was studied in Department of Pharmacology

Research, Defence Services Medical Research Center, Naypyitaw.

Study period

July 2019 to September 2019.

Sample size

Five brands of pure coffee, four brands of instant coffee and five brands of tea samples were studied in this research.

Sampling method

Convenience sampling method was used in this study.

Inclusion criteria

All samples were in good storage condition, good appearance and were not expired.

Exclusion criteria

Any sample damage on any portion of the package. 


\section{International Journal of Engineering Applied Sciences and Technology, 2020 Vol. 5, Issue 4, ISSN No. 2455-2143, Pages 500-504 \\ Published Online August 2020 in IJEAST (http://www.ijeast.com)}

\section{MATERIALS AND METHODS}

Chemicals and apparatus

The following chemicals and materials were used to carry out this study. The chemicals used during this work were methanol (99.99\% or HPLC grade), deionized water (ultrapure grade). Apparatus such as funnel, laboratory bottle, beakers, whatman filter paper, nylon membrane filter $(0.25$ $\mu \mathrm{m})$, air-dry oven, deionized machine and High Performance Liquid Chromatography (HPLC) were used to determine the concentration of caffeine in samples. All the glassware were soaked overnight with detergent solution and washed thoroughly with water, then rinsed with deionized water before use. The chemicals and reagents used in this study were HPLC grade. The five brands of pure coffee, four brands of instant coffee and five brands of tea were purchased from various supermarkets in Naypyitaw. The coffee and tea samples were kept at room temperature throughout the analysis.

Determination of caffeine in coffee and tea samples by HPLC Standard solutions preparation

Caffeine stock standard solution of 1000 ppm was prepared by accurately weighing $100 \mathrm{mg}$ of pure caffeine standard and quantitatively transferring it into $100 \mathrm{ml}$ volumetric flask and making it to the mark with the mobile phase (Water: Methanol, 50:50). Working standards of 6.25, $12.5,25,50,100 \mathrm{ppm}$ was prepared by serial dilution of the stock solution with the mobile phase (Water: Methanol, 50:50).

\section{Sample preparation}

Each $2.00 \mathrm{~g}$ of tea and coffee samples were weighed in triplicate and put into $250 \mathrm{~mL}$ beakers. $100 \mathrm{~mL}$ of boiling distilled water was added and let to stand for 5 minutes with stirring, this solution was cooled and filtered into conical flasks. $5 \mathrm{~mL}$ of the filtrate was pipetted into clean $50 \mathrm{~mL}$ volumetric flasks and was made to the mark with the mobile phase (Water: Methanol, 50:50). The standards and the samples were run in the HPLC system. The following were the HPLC conditions as shown in Table (1).

Table - 1 HPLC experimental condition

\begin{tabular}{|l|l|}
\hline Column & C-18, VP-ODS, $250 \times 4.6 \mathrm{~mm}$ \\
\hline Flow rate & $1 \mathrm{~mL} / \mathrm{min}$ \\
\hline Detector & UVset at $254 \mathrm{~nm}$ \\
\hline Mobile phase & Water : Methanol (50:50) \\
\hline Sample volume & $20 \mu \mathrm{L}$ \\
\hline LC Stop Time & $10 \mathrm{~min}$ \\
\hline $\begin{array}{l}\text { Column Oven } \\
\text { Temperature }\end{array}$ & $36^{\circ} \mathrm{C}$ \\
\hline
\end{tabular}

\section{RESULT}

Linearity

Five different concentrations of caffeine standard solution from $6.25 \mathrm{ppm}$ to $100 \mathrm{ppm}$ were analyzed according to experimental conditions. Then, the calibration curve was established according to the obtained response peak areas and the concentrations of caffeine in standard solutions. There was a good linear relationship between peak areas and the concentrations of caffeine as shown in Figure (1) and (2).

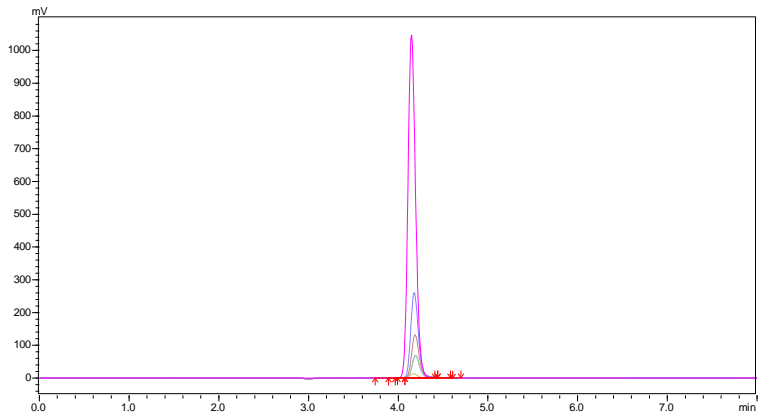

Fig. 1. Chromatograms indicating the peaks of caffeine standard concentrations of $6.25,12.5,25,50,100$ ppm (mg/L) $(\mathrm{Rt}=4.1 \mathrm{~min})$

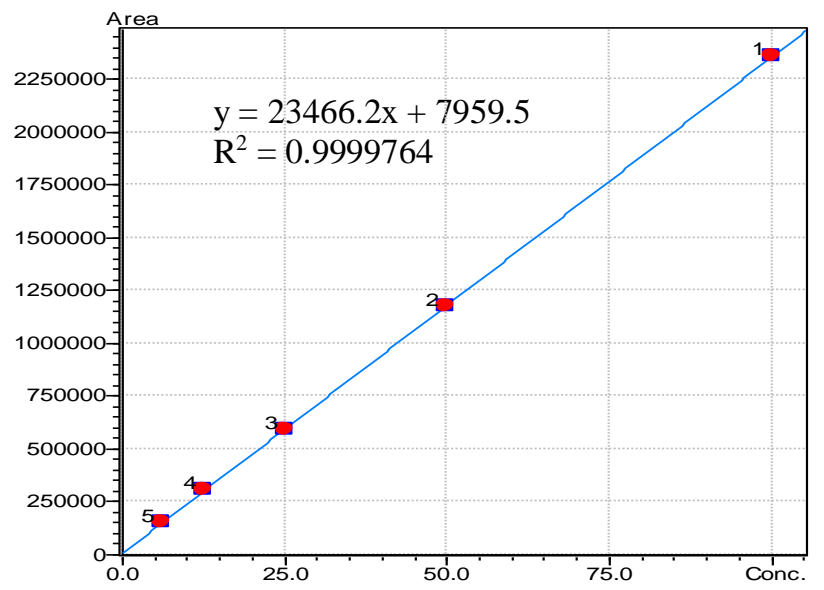

Fig. 2. Calibration curve of caffeine standard

Caffeine concentration in samples

In this study, five different brands of pure coffee, four different brands of instant coffee and five different brands of tea available in the Naypyitaw market were analyzed. The results are shown in Figure (3) and Table (2). 


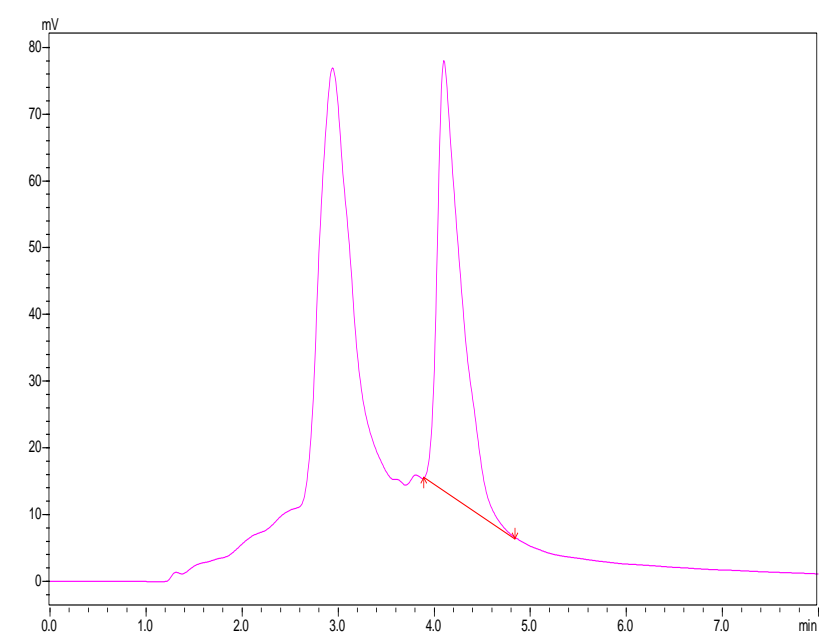

Fig. 3. Representative chromatogram of caffeine from sample extract $\left(\mathrm{R}_{t}=4.1 \mathrm{~min}\right)$

Table - 2 Caffeine level in different brands of pure coffee, instant coffee and tea

\begin{tabular}{|c|c|c|c|c|}
\hline $\begin{array}{l}\text { Type of } \\
\text { Sample }\end{array}$ & $\begin{array}{c}\text { Sample } \\
\text { Code }\end{array}$ & $\begin{array}{c}\text { Concentration } \\
(\mathrm{mg} / \mathrm{g}) \\
\text { Mean } \pm \text { SD } \\
(\mathbf{n = 3})\end{array}$ & $\begin{array}{c}\text { Concentration } \\
\text { (mg/serving) } \\
\text { Mean } \pm \text { SD } \\
(\mathbf{n}=\mathbf{3})\end{array}$ & $\begin{array}{c}\text { Serving } \\
\text { Size }\end{array}$ \\
\hline \multirow{5}{*}{$\begin{array}{l}\text { Pure } \\
\text { Coffee }\end{array}$} & $\mathrm{C1}$ & $2.74 \pm 0.111$ & $547.404 \pm 22.34$ & $200 \mathrm{~g}$ \\
\hline & $\mathrm{C2}$ & $0.87 \pm 0.003$ & $173.05 \pm 0.67$ & $200 \mathrm{~g}$ \\
\hline & C3 & $3.64 \pm 1.39$ & $527.87 \pm 13.93$ & $200 \mathrm{~g}$ \\
\hline & $\mathrm{C4}$ & $5.26 \pm 0.07$ & $1051.20 \pm 14.42$ & $200 \mathrm{~g}$ \\
\hline & C5 & $3.03 \pm 0.004$ & $605.87 \pm 0.93$ & $200 \mathrm{~g}$ \\
\hline \multirow{4}{*}{$\begin{array}{l}\text { Instant } \\
\text { Coffee }\end{array}$} & C6 & $0.28 \pm 0.003$ & $5.12 \pm 0.07$ & $20 \mathrm{~g}$ \\
\hline & C7 & $0.24 \pm 0.002$ & $4.24 \pm 0.04$ & $20 \mathrm{~g}$ \\
\hline & C8 & $0.4 \pm 0.009$ & $7.23 \pm 0.16$ & $20 \mathrm{~g}$ \\
\hline & C9 & $0.31 \pm 0.008$ & $5.66 \pm 0.16$ & $20 \mathrm{~g}$ \\
\hline \multirow{5}{*}{ Tea } & $\mathrm{C10}$ & $0.93 \pm 0.014$ & $16.83 \pm 0.26$ & $20 \mathrm{~g}$ \\
\hline & C11 & $0.92 \pm 0.002$ & $16.71 \pm 0.04$ & $20 \mathrm{~g}$ \\
\hline & $\mathrm{C} 12$ & $0.29 \pm 0.001$ & $5.17 \pm 0.03$ & $20 \mathrm{~g}$ \\
\hline & $\mathrm{C13}$ & $0.79 \pm 0.004$ & $14.35 \pm 0.07$ & $20 \mathrm{~g}$ \\
\hline & C14 & $0.63 \pm 0.002$ & $11.27 \pm 0.04$ & $20 \mathrm{~g}$ \\
\hline
\end{tabular}

\section{DISCUSSION}

In this study HPLC method is very efficient and precise method for determination of caffeine in pure coffee, instant coffee and tea. According to Figure (2), the linearity of calibration curve is acceptable for quantitative determination. According to Table (2), among pure coffee, C4 contain highest concentration and $\mathrm{C} 2$ contain the lowest concentration. And then, among instant coffee, C8 contain highest concentration and $\mathrm{C} 7$ contain the lowest concentration. Among tea samples, $\mathrm{C} 10$ contain highest concentration and C12 contain the lowest concentration. This study showed pure coffee has highest caffeine content followed by tea and instant coffee.
Kebena and Tamene (2013) study showed that caffeine contents in coffee samples were $57.23 \mathrm{mg} / \mathrm{L}$ for Yayo raw coffee, $62.63 \mathrm{mg} / \mathrm{L}$ for Yayo roasted coffee, $59.33 \mathrm{mg} / \mathrm{L}$ for chora raw coffee, $70.93 \mathrm{mg} / \mathrm{L}$ for chora roasted coffee, 64.61 $\mathrm{mg} / \mathrm{L}$ for Mettu raw coffee and $78.68 \mathrm{mg} / \mathrm{L}$ for Mettu roasted coffee. These study found that result Mettu rural coffee bean has highest caffeine content followed by Chora coffee and then yayo coffee. Roasting of coffee in all cases also increases the level of caffeine all coffee samples.

Eva MH (1988) conducted that caffeine content in coffee and tea varies widely depending on the type of coffee bean and the method of preparation. Arabica coffee normally contains less caffeine than the Robusta variety. This variation in caffeine content depends on the type of coffee, cultivation, environment and soil type.

Fajara and Susanti (2017) found that average of caffeine level in coffee bottles of X, Y, and Z were $138.048 \mathrm{mg} /$ bottle, $109.699 \mathrm{mg} / \mathrm{bottle}$, and $147.669 \mathrm{mg} / \mathrm{bottle}$, respectively. The caffeine content of the three coffee beverage samples are statistically different $(p<0.05)$. The levels of caffeine contained in $\mathrm{X}, \mathrm{Y}$, and $\mathrm{Z}$ coffee beverage samples were not meet the requirements set by the Indonesian Standard Agency of $50 \mathrm{mg} /$ serving.

Freedman ND (2012) reveals that during the years 1995 to 2008 , as many as 52.515 peoples in the world died from excessive coffee consumption. Arwangga et al. (2016) conducted according to Indonesian Standard Agency, the allowed caffeine levels are $150 \mathrm{mg} /$ day (SNI 01-3542-2004) and $50 \mathrm{mg} /$ serving (SNI 01-7152-2006) while the USFDA regulation allowed the level of caffeine $<400 \mathrm{mg} /$ day. Therefore, caffeine concentration regulation may be varied according to different countries and this may be due to different ethnics group, genetic and location.

Driesbach et al. (1943) found that excessive intake of caffeine can cause health negative problem and so, public should have the good knowledge in concern with coffee and tea consumption. In the world, the drinking habit of coffee and tea is traditional or modern lifestyle. However, long term excessive intake may be negative impact into heart and psychological effect. The symptoms of caffeine withdrawal, the most common of which is headache, begin 12-24 h after the last dose of caffeine. Griffiths et al. (1990) also found that in addition to headache, other caffeine withdrawal symptoms include tiredness/fatigue, sleepiness/ drowsiness, dysphoric mood (e.g., miserable, decreased well-being/ contentedness), difficulty concentrating/decreased cognitive performance, depression, irritability, nausea/vomiting, and muscle aches/stiffness.

Therefore, public should know how many present caffeine concentration per serving and what level is negative impact level of caffeine especially in infant, children and pregnancy. Regulatory agency should examine the caffeine concentration regularly, and the manufacturer should provide definitely the caffeine concentration label on package for consumer right. 
International Journal of Engineering Applied Sciences and Technology, 2020

Vol. 5, Issue 4, ISSN No. 2455-2143, Pages 500-504

Published Online August 2020 in IJEAST (http://www.ijeast.com)

\section{CONCLUSION}

The findings showed pure coffee has highest caffeine content followed by tea and instant coffee. The consumer should drink not more than USFDA recommended caffeine level $(400 \mathrm{mg} /$ day) especially in pure coffee drinker.

\section{ACKNOWLEDGEMENT}

We are particularly grateful to Professor Kyee Myint, Commandant, Defence Services Medical Research Centre, Naypyitaw, for his kind permission and encouragement to conduct this study. We wish to express our deepest thanks to all the participants and staffs from Defence Services Medical Research Centre.

\section{REFERENCE}

1. Aurnaud MJ.(1987). The pharmacology of caffeine, Prog, 16(3), (pp. 31-273).

2. Barone JJ, Roberts HR.(2013).Caffeine consumption. Food chem. Toxicol, 14(3), (pp. 34-119).

3. http://www.ico.org/caffeine.asp.,Caffeine: International coffee organization. (1996). Retrieved on 2006-08-21. http://www.jeremiahspick.com/caffeine-e-13.html.

4. Eva MH. (1988). Nutrition: West publishing company. 4(7): (pp. 336-351). http://coffeefaq.com/site/node/15. Coffee and caffeine FAQ: Does dark roast coffee have less caffeine than light roast?, Retrieved on 2007- 01- 02.

5. http://www.nobleharbor.com/tea/caffeine.html., Caffeine in tea versus steeping time.(2006).

6. Bolton., Sanford., and Gary N.(1981). Caffeine: Psychological Effects, Use and Abuse. Orthomolecular Psychiatry, 10(3), (pp. 202-211).

7. http://www.polaris.nova.edu/shanbhag/chemistry/oc1labs/c affeine.(2010).

8. Jeanne CS. (1987). Introductory clinical pharmacology. J. B. Uppimcott Company, 3(19): (pp.122-125).

9. Nawrot P., Jordan S., Eastwood J., Rotstein J., Hugenholtz A., and Feeley M. (2003). Effects of caffeine on human health. Food Addit Contam, 20(3), (pp.1-30).

10. Kaplan E., Holmes JH., and Sapeika N. (1974). Caffeine content of tea and coffee. S. Afr. Med. J, 48(4): (pp. 510511).

11. Seifert SM., Schaechter JL., Hershorin ER., and Lipshultz SE. (2011). Health effects of energy drinks on children, adolescents, and young adults. Pediatric; 127(5), (pp.511528).
12. Kebena GM., and Tamene TB.(2013). Determination of caffeine in raw and roasted coffee beans of ilu abba bora zone, south west Ethiopia,124(9), (pp.412-452).

13. Fajara BP., and Susanti H. (2017). HPLC determination of caffeine in coffee beverage. Materials Science and Engineering, 15(8), (pp. 259-261).

14. Freedman ND.(2012).Association of coffee drinking with total and all-cause mortality Nejm, (pp.1-14).

15. Arwangga AF., Asih IA., and Sudiarta IW. (2016). Analisis kandungan kafein pada kopi di desasesaot narmada menggunakan spektrofotometri Uv-Vis. J. Kim. Univ, 10 (1): (pp. 110-114).

16. Driesbach RH., and Pfeiffer C. (1943). Caffeinewithdrawal headache. J. Lab. Clin. Med, 28(12), (pp. 121219).

17. Griffiths RR., Evans SM., Heishman SJ., Preston KL., Sannerud CA., Wolf B., and Woodson PP. (1990). Lowdose caffeine physical dependence in humans. J. Pharmacol. Exp. Ther, 255(45), (pp. 1123-1132). 